\title{
The Reliability and Validity of the Brief ICF Core Set in Patients with Chronic Obstructive Pulmonary Disease
}

\author{
Yongmei Zhang, ${ }^{1} *$ Xiaoxuan \\ Meng, ${ }^{1} *$ Yuehao Shen, ${ }^{2} *$ Jiajia \\ Xie, ${ }^{2} \mathrm{Xi}$ Yu, $\mathbb{D}^{3}$ Qiaoshuo \\ Wang, ${ }^{4}$ Lan Wang ${ }^{1}{ }^{1}$
}

'School of Nursing, Tianjin Medical University, Tianjin, People's Republic of China;

${ }^{2}$ Department of Respiratory Care, General Hospital of Tianjin Medical University, Tianjin, People's Republic of China; ${ }^{3}$ Department of Respiratory Care, Tianjin First Center Hospital, Tianjin, People's Republic of China; ${ }^{4}$ Department of Cardiac Care, Tianjin Chest Hospital, Tianjin, People's Republic of China

*These authors contributed equally to this work

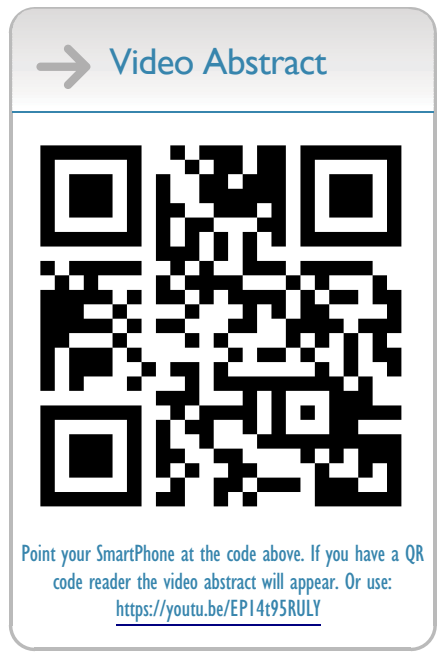

Correspondence: Lan Wang School of Nursing, Tianjin Medical University, 22 Qi Xiang Tai Road, Heping District, Tianjin, 300070, People's Republic of China

Tel +862283336913

$\mathrm{Fax}+862283336900$

Email wang10423@tmu.edu.cn
Purpose: To analyze the reliability and validity of the Brief international classification of functioning, disability and health (ICF) core set for chronic obstructive pulmonary disease (COPD).

Patients and Methods: A cross-sectional study was conducted in four tertiary hospitals in Tianjin, China. A total of 100 patients with COPD were selected to evaluate functioning and disability involving body functions, body structures, activities and participation as well as environmental factors of the Brief ICF core set for COPD. Internal consistency was calculated by Cronbach's $\alpha$. Content validity was examined using the content validity index (CVI), scale-level CVI/universal agreement, and scale-level CVI/average agreement (S-CVI/Ave). In addition, construct validity and convergent validity were also examined.

Results: The Brief ICF core set for COPD had a high internal consistency, 0.873 for the total scale, with values of $0.750,0.640$, and 0.843 for body functions, body structures, and activity and participation, respectively. The content validity was calculated by the CVI, scale-level CVI/universal agreement, and S-CVI/Ave at values of 0.80-1, 0.929, and 0.986, respectively. Meanwhile, the ICF core set for COPD had good convergent validity, correlating with the mMRC dyspnea score $(r=0.690, P<0.01)$, and there were significant correlations between the ICF core set for COPD and COPD clinical severity grade $(r=0.363, P<0.01)$. A four-factor model of functions and disability in the Brief ICF core set for COPD had the best fit according to confirmatory factor analysis (CFA).

Conclusion: The Brief ICF core set for COPD is a reliable and valid convenient instrument for assessing comprehensive problems in the functioning of patients with COPD, which can be used to design and to evaluate rehabilitation strategies.

Keywords: international classification of functioning, disability and health, chronic obstructive pulmonary disease, reliability, validity

\section{Introduction}

Chronic obstructive pulmonary disease (COPD) has significant morbidity and mortality and poses a major health and economic burden to patients' families and nationwide. ${ }^{1}$ As stated by Global Initiative for Chronic Obstructive Lung Disease (GOLD) 2021, in an update on the disease burden of COPD, the incidence of this disease is expected to continue to rise over the next 40 years, resulting in more than 5.4 million deaths a year from COPD and related diseases by 2060 as smoking rates increase in developing countries and population aging accelerates in high-income countries. $^{2}$ GOLD has reported pulmonary rehabilitation is one of the content of the standard treatment for COPD. ${ }^{2}$ However, whether the intervention is effective 
depends on considering the complexity and severity individualized to the unique needs of the patients. ${ }^{3}$ Therefore, it is especially important to assess the patient's physical function and structure effectively to explain further the performance of daily activities and participation in life pursuits. The World Health Organization International Classification of Functioning, Disability and Health (ICF) provides the basis for such an assessment system that offers a useful framework for classifying the components of health and consequences of a disease. In addition, this classification aims to provide a unified and standard language for the description of health conditions in rehabilitation and a common framework for all health professions to promote exchanges between different disciplines and fields around the world. ${ }^{4}$ The ICF provides functional measurements for patients with COPD and combines the living environment to analyze the interaction and relationship between the state of health (diseases, disorders and injuries) and contextual factors. This framework specifically includes four aspects: body function, body structure, activity and participation and contextual factors. The ultimate goal of using ICF is to use it as a common classification and language system which can be used more widely in health care services. A preliminary study on the reliability and validity of the ICF-COPD Core Set was analyzed by Liu, ${ }^{5}$ and the results showed that the evaluation function for patients with COPD was reliable and effective, but its universality still needs to be further tested in more studies.

To promote more clinical practice and generalization of the ICF for chronic disease, WHO has developed the ICF core set based on various applied research projects in recent years. For instance, validates the ICF core set for obstructive pulmonary diseases from the perspective of adults with asthma; ${ }^{6}$ to validate the ICF core set for hearing loss (HL) of adults with HL internationally; ${ }^{7}$ and to ensure the ICF core set for cerebral palsy (CP) applicability by using the child and youth national dataset in Taiwan and the Functioning Scale of the Disability Evaluation System, ${ }^{8}$ which has good functionality and time efficiency. The ICF core set selects as few ICF items as possible related to function, disability and health under specific disease and environmental conditions. The brief core set, which extracts the most commonly suitable items from the core set, is the key to applying the ICF in clinical applications. The Brief ICF core set has been widely used in various fields to evaluate function, and a number of mature assessment sets have been developed.
This core set plays an important role in guiding clinical nursing and rehabilitation work. Currently, the Brief ICF core set has received research certification, such as for chronic widespread pain, ${ }^{9}$ low back pain, ${ }^{10}$ osteoarthritis, ${ }^{11}$ osteoporosis, ${ }^{12}$ rheumatoid arthritis, ${ }^{13}$ chronic ischemic heart disease, ${ }^{14}$ depression, ${ }^{15}$ breast cancer, ${ }^{16}$ stroke, ${ }^{17}$ and spinal cord injury. ${ }^{18}$ The Brief ICF is also emphasized as a reference framework to evaluate and to compare the coverage of other models in clinical practice. ${ }^{19}$

By combining evidence and expert opinion, the first Brief ICF core set for obstructive pulmonary disease (OPD) patients was developed, consisting of 4 components and 14 categories, in $2004 .^{20}$ The applicability of the scale has been largely supported by physiotherapists and clinical experts, ${ }^{21,22}$ and it was further verified by patients. ${ }^{23}$ In addition, Marques and other scholars also pointed out, which has not been confirmed, the additional categories that were raised need further investigation in the Brief ICF core set. ${ }^{24}$ Huang proposed through research that there is a high prevalence of problems in 8 categories that were not considered in the Brief ICF-OPD core set for patients with COPD. ${ }^{25}$ Recent studies have shown that the Brief ICF core set has good reliability and validity on the part of "activity and participation" and can be used to test daily activities for patients with COPD. ${ }^{26}$ Current studies on the Brief ICF core set for COPD lack an overall assessment of the four dimensions, which needs further confirmation.

By using the clinical data, Brief ICF core set was preliminarily studied to verify their reliability and validity and to provide an objective basis for their clinical application. According to the conclusion of the former study, suggestions for improvement of the Brief ICF core set for COPD were put forward. In addition, the Brief ICF core set will have different problems because of cultural and environmental discrepancies, thus the Brief ICF core set for COPD still needs further study. Therefore, the aim of this study is to test the reliability and validity of the Brief ICF Core Set for patients with COPD to provide an objective basis for its clinical application, which will lay the foundation for its further application in China.

\section{Patients and Methods}

\section{Study Design}

The study was designed as a cross-sectional survey. The research site was four tertiary hospitals, Tianjin Medical 
University General Hospital, The Second Hospital of Tianjin Medical University, The Tianjin First Central Hospital, and The Tianjin Chest Hospital. This study was conducted in accordance with the Declaration of Helsinki and approved by the Ethics Committee of Tianjin Medical University (TMUhMEC2020028).

\section{Patients}

The study subjects were patients with COPD who visited the four tertiary hospitals from October 2019 to October 2020. The inclusion criteria were as follows: (1) meeting the diagnostic criteria of the Global Initiative on Chronic Obstructive Pulmonary Disease (GOLD): the global strategy for diagnosis, treatment, and prevention of COPD (updated); and (2) signing a written informed consent form. The exclusion criteria were as follows: (1) having complications with severe primary diseases, such as cardiovascular, liver, kidney, and brain diseases; (2) being unable to respond to the instructions of the research.

According to the empirical method, the sample size is at least $5-10$ times as large as the number of measured items, and there are 14 questions in total. At the same time, considering the possibility of invalid questionnaires, the sample size was increased by $10 \%$. Finally, 100 patients with COPD were selected as research subjects. $^{27}$

\section{Instruments}

\section{Social Demographic and Clinical Variables}

The demographic variables included sociodemographic variables such as age, sex, height, weight, body mass index (BMI $\mathrm{kg} / \mathrm{m} 2$ ), marital status, education level, employment status, income level, and smoking history, as well as clinical variables such as course of disease, stage of illness, family history, complications, use of drugs and home oxygen.

\section{The Brief ICF-COPD Core Set}

In this study, the Brief ICF-COPD Core Set was used to assess functioning and disability involving body functions, body structures, activities and participation as well as environmental factors in all patients. This Brief ICF Core Set comprises four categories in body functions, two categories in body structures, four categories in activities and participation, and four categories in environmental factors (Table 1). ICF qualifiers were applied to rate the degree of problems in each category of the body function and
Table I The Contents of the Brief ICF-COPD Core Set

\begin{tabular}{|c|c|c|}
\hline Component & Code & Category \\
\hline $\begin{array}{l}\text { Body } \\
\text { Functions }\end{array}$ & $\begin{array}{l}\mathrm{b} 440 \\
\mathrm{~b} 450 \\
\mathrm{~b} 455 \\
\mathrm{~b} 460\end{array}$ & $\begin{array}{l}\text { Respiration functions } \\
\text { Additional respiratory functions } \\
\text { Exercise tolerance functions } \\
\text { Sensations associated with cardiovascular } \\
\text { and respiratory functions }\end{array}$ \\
\hline $\begin{array}{l}\text { Body } \\
\text { structures }\end{array}$ & $\begin{array}{l}s 410 \\
s 430\end{array}$ & $\begin{array}{l}\text { Structure of cardiovascular system } \\
\text { Structure of respiratory system }\end{array}$ \\
\hline $\begin{array}{l}\text { Activity and } \\
\text { Participation }\end{array}$ & $\begin{array}{l}d 230 \\
d 450 \\
d 455 \\
d 640\end{array}$ & $\begin{array}{l}\text { Carrying out daily routine } \\
\text { Walking } \\
\text { Moving around } \\
\text { Doing housework }\end{array}$ \\
\hline Environment & $\begin{array}{l}\text { ello } \\
\text { ell5 } \\
\text { e225 } \\
\text { e260 }\end{array}$ & $\begin{array}{l}\text { Products of substances for personal } \\
\text { consumption } \\
\text { Products and technology for personal use } \\
\text { in daily living } \\
\text { Climate } \\
\text { Air quality }\end{array}$ \\
\hline
\end{tabular}

Notes: Adapted from Stucki A, Stoll T, Cieza A, et al. ICF Core Sets for obstructive pulmonary diseases. J Rehabil Med. 2004;36:1 14-120. (C) 2004 Taylor \& Francis. ${ }^{20}$

structures component and activity participation component with a generic five-point scale: $0,1,2,3$, and 4 , indicating no problem, mild problem, moderate problem, severe problem, and complete problem, respectively. Environmental factors were graded with a nine-point scale: $+4,+3,+2$, $+1,0,1,2,3$, and 4 , indicated to complete facilitator, substantial facilitator, moderate facilitator, mild facilitator, no barrier/facilitator, mild barrier, moderate barrier, severe barrier, and complete barrier. In addition, score numbers eight and nine also indicated unspecified and not applicable, respectively, in all categories.

\section{Modified British Medical Research Council (mMRC)}

The mMRC dyspnea score is a 5-point (0-4) scale based on the severity of dyspnea. ${ }^{28}$ The MRC dyspnea scale rates breathlessness by the following responses: $0=$ "I am never breathless or short of breath;" 1="I only get breathless with strenuous exercise;" 2="I get short of breath when hurrying on the level or up a slight hill;" $3=$ "I walk slower than people of the same age on the level because of breathlessness or have to stop for breath when walking at my own pace on the level;" 4="I stop for breath after walking 100 yards or after a few minutes on the level;" or 5="I am too breathless to leave the house." 


\section{COPD Clinical Severity Grade}

The severity of airfow limitation in COPD is classified based on post-bronchodilator FEV1 value into four groups (GOLD1, GOLD2, GOLD3, and GOLD4, from 1 to 4 in score). ${ }^{2}$ In patients with $\mathrm{FEV} 1 / \mathrm{FVC}<70 \%$, if $\mathrm{FEV} 1>80 \%$ predicted, they are classified as mild (GOLD1), if FEV1 predicted $<80 \%$ and $\geq 50 \%$ as moderate (GOLD2), if FEV1predicted $<50 \%$ and $\geq 30 \%$ as severe (GOLD3) and if FEV1predicted $<30 \%$ as very severe (GOLD4) airfow limitation.

\section{Data Collection}

Descriptive data were collected by interviewing the participants and by consulting their medical records. Data collection was performed by four raters in different hospitals with relevant research experience who had previously been trained in data collection skills. After confirming that the patients met the inclusion criteria, raters explained the purpose and content of the study to them and helped patients sign the informed consent form.

\section{Data Analysis}

Statistical analyses were performed using SPSS version 25.0 (IBM Corp, New York) and AMOS version 24.0 (IBM Corp, New York). The 0.05 level of significance was applied. Descriptive statistics were conducted to describe participant sociodemographic and clinical variables. Quantitative variables are presented as the mean \pm standard deviation. Qualitative variables are presented as frequencies (percentages).

\section{Internal Consistency Reliability}

For the reliability test, the internal consistency was analyzed and expressed by Cronbach's $\alpha$ coefficients. Data from 100 patients with COPD were collected to assess the internal reliability. A Cronbach's $\alpha>0.7$ is considered to be the acceptable value for reliability. ${ }^{29}$

\section{Content Validity}

To identify whether the Brief ICF-COPD Core Set could cover the most common problems in patients with COPD, we used expert consultation to study the content validity. The content validity index (CVI) was determined by an expert panel group including 5 specialists (they all possessed Senior title of professional). Three levels of the CVI, item level (I-CVI), scale level (S-CVI) and S-CVI/ AVE, were computed to evaluate the content validity. The I-CVI was evaluated with a 4-point rating scale and was calculated by the formula (the number of experts who marked 3 or $4 /$ the total number of experts). The S-CVI is equal to the proportion of items rated 3 or 4 by all experts. The S-CVI/AVE was tested by taking the average of the item-level CVIs. The finding of an S-CVI greater than 0.80 and an I-CVI greater than 0.78 indicates acceptable content validity. $^{30}$

\section{Construct Validity}

To evaluate the construct validity of the Brief ICF-COPD Core Set in the Chinese context, factor analysis was conducted. Confirmatory factor analysis (CFA) was performed with the maximum likelihood method to confirm the structure of the Brief ICF-COPD Core Set. The criteria for goodness-of-fit indices included $\chi^{2}$ statistics/degrees of freedom $\left(\chi^{2} / \mathrm{df}\right)$ of less than 3 , a standardized root mean square residual of less than 0.08 , and an incremental fit index closer to $1.31,32$

\section{Convergent Validity}

The GOLD proposed a new severity assessment system for emphasizing clinical system evaluation by mMRC dyspnea scores, and COPD clinical severity grade is also an important assessment system. GOLD reports the complete flow chart of COPD management and grouping criteria, in which $\mathrm{mMRC}$ is used to preliminarily evaluate the symptoms of patients. ${ }^{2}$ To evaluate the convergent validity of the Brief ICF-COPD Core Set, we analyzed the relationship between the score of the Brief ICF-COPD Core Set, mMRC dyspnea scores and COPD clinical severity grade. The mMRC dyspnea score is a 5-point (0-4) scale based on the severity of dyspnea. The COPD clinical severity grade is a 4-point (I-IV) scale. To investigate the criterion validity of the Brief ICF-COPD Core Set, Pearson correlation coefficients between the scores of the core set components and the mMRC or COPD clinical severity grade were calculated. As recommended, correlation coefficients were interpreted as follows: weak correlation (0.10-$0.39)$, moderate correlation $(0.40-0.69)$, strong correlation (0.70-0.89), and very strong correlation $(0.90-1.00) .^{33}$ We hypothesized that positive correlations were found between overall and component scores of the Brief ICF-COPD Core Set and mMRC dyspnea scores or COPD clinical severity grade, and higher scores in the Brief ICF-COPD Core Set corresponded to higher scores in the mMRC and COPD clinical severity grade. 


\section{Result}

\section{Social Demographic and Clinical Variables}

A total of 100 patients with COPD were included in this study, consisting of 69 males and 31 females. The average age was $70.70 \pm 8.07$. Approximately, $52 \%$ of the patients were referred for a smoking history, and $78 \%$ of patients

Table 2 Sociodemographic and Clinical Variables $(\mathrm{N}=100)$

\begin{tabular}{|c|c|}
\hline Items & $\mathbf{N}(\%)$ \\
\hline \multicolumn{2}{|l|}{ Sex } \\
\hline Male & $69(69)$ \\
\hline Female & $3 \mid(3 I)$ \\
\hline \multicolumn{2}{|l|}{ Age, range 52-91 } \\
\hline$<60$ & $8(8)$ \\
\hline $60-70$ & $35(35)$ \\
\hline $70-80$ & $43(43)$ \\
\hline$\geq 80$ & $14(14)$ \\
\hline \multicolumn{2}{|l|}{ BMI (kg/m2) } \\
\hline$<18.5$ & $14(14)$ \\
\hline $18.5-23.9$ & $53(53)$ \\
\hline $24.0-27.9$ & $23(23)$ \\
\hline$\geq 28$ & $10(10)$ \\
\hline \multicolumn{2}{|l|}{ Marital status } \\
\hline Married & 9I (9I) \\
\hline Divorced/widowed & $9(9)$ \\
\hline \multicolumn{2}{|l|}{ Mode of residence } \\
\hline Live with spouse/children & $96(96)$ \\
\hline Live alone & $4(4)$ \\
\hline \multicolumn{2}{|l|}{ Education level } \\
\hline Illiterate & $4(4)$ \\
\hline Primary school & $22(22)$ \\
\hline Middle school & $38(38)$ \\
\hline High school & $30(30)$ \\
\hline College or above & $6(6)$ \\
\hline \multicolumn{2}{|l|}{ Financial situation } \\
\hline Income & 7I (7I) \\
\hline Children's allowance & $23(23)$ \\
\hline Other allowance & $2(2)$ \\
\hline No income or support & $4(4)$ \\
\hline \multicolumn{2}{|l|}{ Health insurance } \\
\hline Yes & $93(93)$ \\
\hline No & 7 (7) \\
\hline \multicolumn{2}{|l|}{ Smoking } \\
\hline Current smokers & $27(27)$ \\
\hline Ex-smokers & $25(25)$ \\
\hline Non smokers & $48(48)$ \\
\hline
\end{tabular}

(Continued)
Table 2 (Continued).

\begin{tabular}{|l|l|}
\hline Items & N (\%) \\
\hline Course of disease & \\
Acute exacerbation of COPD & $78(78)$ \\
Stable COPD & $22(22)$ \\
\hline GOLD & \\
I & $16(16)$ \\
II & $50(50)$ \\
IV & $23(23)$ \\
\hline COPD exacerbation frequency in the last year (M $\pm S D)$ & $11(11)$ \\
\hline Family history & $1.15(1.14)$ \\
Yes & \\
No & $33(33)$ \\
\hline Complications & $67(67)$ \\
Yes & \\
No & $87(87)$ \\
\hline Use of drugs & $13(13)$ \\
Yes & \\
No & $94(94)$ \\
\hline mMRC & $6(6)$ \\
0 & $26(26)$ \\
I & $19(19)$ \\
3 & $32(32)$ \\
\hline No & $21(21)$ \\
\hline Use of home oxygen & $58(58)$ \\
\hline
\end{tabular}

were in the acute exacerbation stage. Each patient's severity of disease and mMRC dyspnea score varied to some degree. Ninety-four percent of patients had a medication history, and less than half (42\%) of patients received home oxygen therapy. The patient sociodemographic and clinical variables are presented in Table 2.

\section{Internal Consistency Reliability}

Cronbach's $\alpha$ was used to examine the internal consistency of the items within each subscale. The internal consistency was 0.873 for the total scale, with values of $0.750,0.640$, and 0.843 for body functions, body structures, and activity and participation, respectively. Accordingly, Cronbach's $\alpha$ for the total scale and two subscales was higher than 0.70 , indicating sufficient internal consistency (Table 3). 
Table 3 The Internal Consistency Reliability of the Total Scale and Three Subscales

\begin{tabular}{|l|l|l|}
\hline Component & Items & Cronbach's $\boldsymbol{\alpha}$ \\
\hline Body Functions & 4 & 0.750 \\
Body structures & 2 & 0.640 \\
Activity and Participation & 4 & 0.843 \\
Total & 10 & 0.873 \\
\hline
\end{tabular}

\section{Content Validity}

Based on the opinions of the 5 specialists in clinical nursing and therapy, the results of the content validity analysis showed that the I-CVI ranged from $0.8-1.0$, and the S-CVI/universal agreement and S-CVI/AVE were 0.929 and 0.986 , respectively, indicating satisfactory content validity (Table 4).

\section{Confirmatory Factor Analysis}

The construct validity was examined by means of CFA. The initial fit indices of the five-factor model (Figure 1) did not meet the criteria, and the structural model (Figure

2) was modified based on the results of the indices, resulting in a better model fit (Table 5). The results of the CFA were acceptable: $\chi^{2} / \mathrm{df}=1.292$, root mean square error of approximation $=0.054$, Tacker-Lewis inde $x=0.946$, comparative fit index $=0.961$ and incremental fit index $=0.962$. The path diagram from CFA is depicted in Figures 1 and 2.

\section{Convergent Validity}

For convergent validity, moderate correlations were found between the Brief ICF-COPD Core Set and mMRC dyspnea. As expected, the body function scores of the Brief ICF-COPD Core Set correlated positively with the mMRC dyspnea score $(\mathrm{r}=0.582, \mathrm{P}<0.01)$. Similarly, 2 subscales of the Brief ICF-COPD Core Set had positive associations with the mMRC dyspnea score: body structures $(\mathrm{r}=0.458, \mathrm{P}<0.01)$ and activity and participation $(r=0.649, P<0.01)$. However, the environment of the Brief ICF-COPD Core Set had no correlation with the mMRC dyspnea score $(\mathrm{P}>0.05)$. There were relatively weak correlations between the first three subscales (body function, body structures, and activity and participation) of the Brief ICF-COPD Core Set and COPD clinical severity grade as correlation coefficients ranged from 0.177 to $0.363(\mathrm{P}<0.01)$. The total Brief ICF-COPD Core Set score had a moderate correlation with the mMRC dyspnea score $(\mathrm{r}=0.616, \mathrm{P}<0.01)$ and a weak correlation with the COPD clinical severity grade $(r=0.253$, $\mathrm{P}<0.05$ ) (Table 6).

\section{Discussion}

The purpose of our study was to verify the reliability and validity of the Brief ICF-COPD core set and to provide an objective basis for its clinical application. To our knowledge, the Brief ICF-COPD core set was developed by 17 experts with different professional backgrounds from 8

Table 4 Experts' Rating and CVI Calculation $(n=5)$

\begin{tabular}{|c|c|c|c|c|c|c|c|}
\hline \multirow[t]{2}{*}{ Item* } & \multicolumn{5}{|c|}{ Expert Ratings ${ }^{a}$} & \multirow[t]{2}{*}{$\mathbf{I}-\mathrm{CVI}^{\mathrm{b}}$} & \multirow[t]{2}{*}{ S-CVI/AVE } \\
\hline & $\mathbf{A}$ & B & C & D & $\mathbf{E}$ & & \\
\hline b440 Respiration functions & 4 & 4 & 4 & 4 & 4 & 1.00 & \\
\hline b450 Additional respiratory functions & 4 & 2 & 4 & 4 & 4 & 0.80 & \\
\hline b455 Exercise tolerance functions & 4 & 4 & 4 & 4 & 4 & 1.00 & \\
\hline b460 Sensations associated with cardiovascular and respiratory functions & 4 & 4 & 4 & 4 & 4 & 1.00 & \\
\hline s410 Structure of the cardiovascular system & 4 & 4 & 4 & 4 & 4 & 1.00 & \\
\hline s430 Structure of the respiratory system & 4 & 4 & 4 & 4 & 4 & 1.00 & \\
\hline d230 Carrying out daily routine & 4 & 4 & 4 & 4 & 4 & 1.00 & 0.986 \\
\hline d450 Walking & 4 & 4 & 4 & 4 & 4 & 1.00 & \\
\hline d455 Moving around & 4 & 4 & 4 & 4 & 4 & 1.00 & \\
\hline d640 Doing housework & 4 & 4 & 3 & 4 & 3 & 1.00 & \\
\hline el I0 Products or substances for personal consumption & 4 & 4 & 4 & 4 & 4 & 1.00 & \\
\hline elI 5 Products and technology for personal use in daily living & 4 & 4 & 4 & 4 & 4 & 1.00 & \\
\hline e225 Climate & 4 & 4 & 4 & 4 & 4 & 1.00 & \\
\hline e260 Air quality & 4 & 4 & 4 & 4 & 4 & 1.00 & \\
\hline
\end{tabular}

Notes: ${ }^{a}$ Ratings of five experts for the I4-item Brief ICF-CPOD Core Set. ${ }^{\mathrm{b}} \mathrm{According}$ to the criteria for I-CVI, a scale with an I-CVI value $\geq 0.78$ was considered acceptable. *Items adapted from Stucki A, Stoll T, Cieza A, et al. ICF Core Sets for obstructive pulmonary diseases. J Rehabil Med. 2004;36:1 I4-120. ${ }^{20}$ @ 2004 Taylor \& Francis. Abbreviations: CVI, content validity index; I-CVI, item-level CVI. 


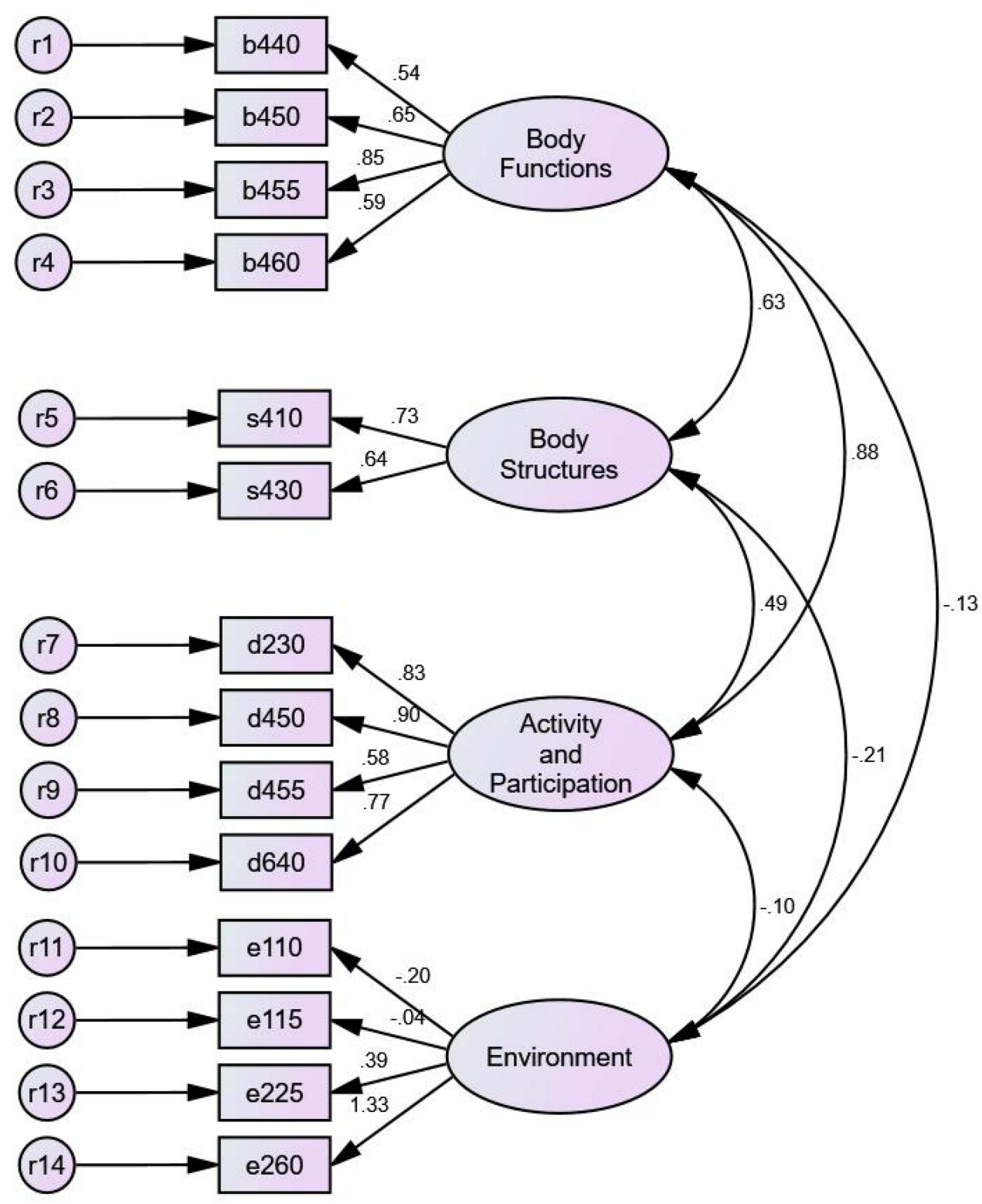

Figure I The initial confirmatory factor analysis result of the Brief ICF-COPD Core Set $(n=100)$.

different countries. ${ }^{34}$ This assessment tool has a high degree of authority and credibility. This study indicates that the Brief ICF-COPD core set was consistent with the original version and can be used to assess impairments in body function and body structure, limitations in activity and participation and to explore environmental influences in Chinese patients with COPD.

The results from the current study supported both the reliability and validity of the Brief ICF-COPD core set. The Cronbach's $\alpha$ correlation coefficient of the Brief ICF-COPD core set total scale was 0.873 in this study, reflecting that the internal consistency of the total scale was acceptable Cronbach's $\alpha$ for body function and activity and participation was also higher than 0.70 . At the same time, the body structure was only 0.640 , indicating that the internal consistency was not great. The possible reasons are as follows: (1) the number of items in this component is too small; (2) the content or characteristics of respiratory structure and cardiovascular structure are not identical. Moreover, some experts also referred to only the category structure of the respiratory system (s430), which was enough as part of the component body structures of the Brief ICF core set. ${ }^{20}$ 


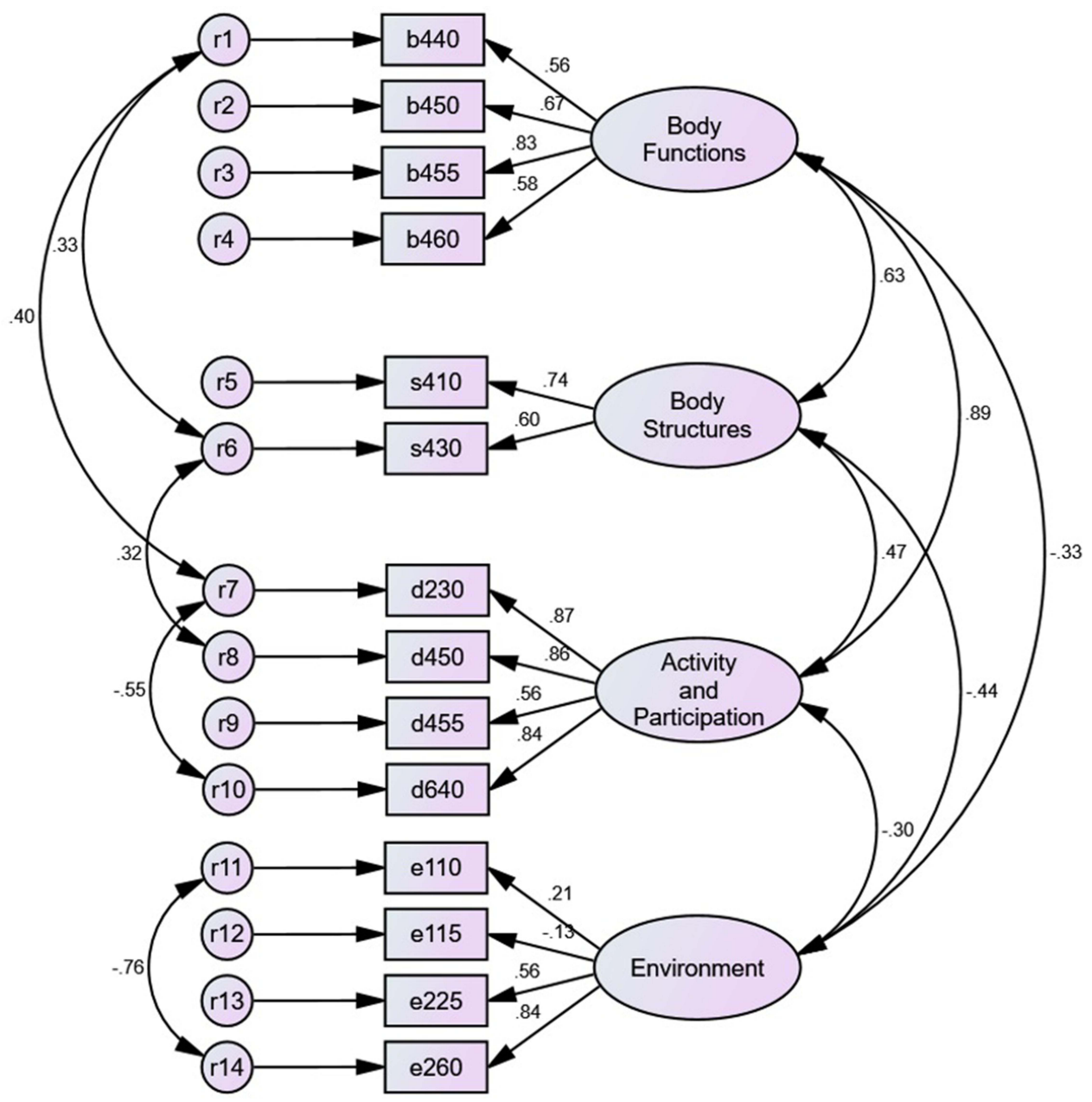

Figure 2 The modified confirmatory factor analysis result of the Brief ICF-COPD Core Set $(n=100)$.

The Brief ICF-COPD Core Set revealed good content validity in this study. The results showed that the I-CVI of 14 items except b450 was 1.00 (the I-CVI of b450 was 0.80 ). An I-CVI of 0.78 was the cutoff for either removing or retaining an item. According to the criteria of content validity, b450 (additional respiratory functions) was retained. Meanwhile, the S-CVI was greater than 0.80 (S-CVI was 0.943 ), which indicated satisfactory content validity.

In summary, adequate construct validity has been evidenced using CFA and convergent validity statistical approaches. With respect to the CFA (model 1, Figure 1), not all fit indices in the initial model met the criteria. Only the

Table 5 Confirmatory Factor Analysis Results

\begin{tabular}{|l|l|l|l|l|}
\hline Model & IFI & TLI & CFI & RMSEA \\
\hline Model I & 0.902 & 0.869 & 0.898 & 0.084 \\
Model 2 & 0.962 & 0.946 & 0.961 & 0.054 \\
\hline
\end{tabular}

fit index IFI was better than 0.9 , so we adjusted the initial model. The model was modified by adding double arrows between the following factors according to the correction index. (1) Respiration functions (b440) and structure of

Table 6 The Correlation of mMRC Dyspnea Score and COPD Clinical Severity Grade with the Respective Scales of the Brief ICF-COPD Core Set

\begin{tabular}{|l|l|l|}
\hline & mMRC & $\begin{array}{l}\text { COPD Clinical Severity } \\
\text { Grade }\end{array}$ \\
\hline Body Functions & $0.582^{\mathrm{b}}$ & $0.316^{\mathrm{b}}$ \\
Body Structures & $0.458^{\mathrm{b}}$ & $0.177^{\mathrm{b}}$ \\
Activity and & $0.649^{\mathrm{b}}$ & $0.363^{\mathrm{b}}$ \\
Participation & -0.194 & $-0.250^{\mathrm{d}}$ \\
Environment & $0.616^{\mathrm{b}}$ & $0.253^{\mathrm{d}}$ \\
\hline Total & \multicolumn{2}{|l}{} \\
\hline
\end{tabular}

Notes: ${ }^{\mathrm{b}} \mathrm{p}<0.01$; ${ }^{\mathrm{d}} \mathrm{p}<0.05$

Abbreviations: mMRC, modified British Medical Research Council; The Brief ICFCOPD Core Set, International Classification of Functioning, Disability, and Health Brief Core Set for Chronic Obstructive Pulmonary Disease; GOLD, Global Initiative for Chronic Obstructive Lung Disease. 
respiration system (s430): The pathological process of COPD can lead to repeated circulation of airway wall injury and repair process. The repair process leads to the remodeling of airway wall structure, the increase of collagen content and the formation of scar tissue, resulting in airway stenosis and fixed airway obstruction, which leads to the restricted airflow in COPD and the change of respiratory rhythm, depth and frequency; namely, the change of respiratory function. ${ }^{34}$ (2) respiration functions (b440) and carrying out daily routine (d230): Chronic inflammation of airway mucosa, the parenchyma and pulmonary vessels, as well as remodeling of lung ventilation and ventilation function are affected, resulting in changes in respiratory function such as insufficient alveolar ventilation, resulting in hypoxemia, resulting in insufficient oxygen supply to important organs, such as the heart, brain and kidney, resulting in functional and organic damage and affecting patients' ability to carry out a daily routine. ${ }^{35}$ (3) structure of respiration system (s430) and walking (d450): Patients with COPD are characterized by small airway lesions. When COPD progresses to a certain extent, extensive small airway dysfunction and partial complete destruction of small airways will appear, which are the clinical manifestations of structural changes in the respiratory system, leading to pulmonary hyperventilation and emphysema and the secondary manifestations of decreased diffuse function. ${ }^{36,37}$ Zeng showed that with the deterioration of pulmonary ventilation function, the increase in airway resistance, the decrease in diffusion function and quality of life in patients with COPD, and the six-minute walk test decreased accordingly. ${ }^{38}$ Therefore, there is a correlation between changes in the structure of the respiratory system and walking. (4) carrying out daily routine (d230) and doing housework (d640): Activity of daily living (ADL) includes basic activity of daily living (BADL) and instrumental activity of daily living (IADL). IADL refers to a number of necessary activities for a person to live independently, such as doing housework, cooking, making phone calls, taking medicine, shopping and managing money. ${ }^{39}$ Therefore, there is a correlation between carrying out daily routines and doing housework. (5) Products of substances for personal consumption (e110) and air quality (e260): The 2020 GOLD guidelines state that COPD is usually caused by long-term exposure to harmful particles or gases and air pollution, which can worsen the illness. ${ }^{40}$ Therefore, each medication regimen should be individualized according to the severity of the symptoms. In the case of air pollution, some patients complained that the effects of the drugs they took might not be better than before (item d230 includes food and drugs), so there is a correlation between products or substances for personal consumption and air quality. Compared with the original research, the modified 4-factor model (model 2, Figure 2) showed a better model fit.

The convergent validity of the Brief ICF-COPD Core Set was supported by significant correlations between the mMRC and COPD clinical severity grade. The correlation coefficients between mMRC scores and body functions, body structures, and activity and participation of the Brief ICF-COPD Core Set showed moderate correlations (0.458-0.690) in the present study, indicating acceptable convergent validity. ${ }^{33}$ Nevertheless, the correlation between COPD clinical severity grade and all respective scales/total of the Brief ICF-COPD Core Set was weak $(-0.250,0.177-0.363)$. The most likely reason is that the clinical severity of COPD diagnosed solely on the basis of lung function is not consistent with the degree of daily functional and structural impairment following the onset of the disease. Marin et al showed that the pulmonary function test results of patients with COPD at rest can only reflect the respiratory symptoms of patients in daily life to a certain extent, while the dyspnea of patients with COPD is mainly manifested after exercise, so it is limited to evaluate the severity of COPD only by the pulmonary function test results at rest. ${ }^{41}$

Several limitations need to be addressed in this study: (1) The participants were considered to be representative of Chinese patients with COPD who live in Tianjin city, and these patients may not be generalizable to the overall population in China. Therefore, future studies should recruit more participants from different regions. (2) The majority of participants were inpatients, with fewer outpatients, who had more severe or acute disease. The origin of the patients may have influenced the results of the study. (3) In terms of reliability in the research, this study did not involve interrater reliability, which may lead to investigator bias in these results.

\section{Conclusion}

The Brief ICF-COPD core set is a reliable and valid convenient instrument for assessing comprehensive problems in the functioning of patients with COPD. Based on the outcomes of the Brief ICF-COPD, rehabilitation strategies can be set. Meanwhile, the instrument may be used to monitor the long-term effects of rehabilitation and self-care. 


\section{Author Contributions}

All authors made a significant contribution to the work reported, whether that is in the conception, study design, execution, acquisition of data, analysis and interpretation, or in all these areas; took part in drafting, revising or critically reviewing the article; gave final approval of the version to be published; have agreed on the journal to which the article has been submitted; and agree to be accountable for all aspects of the work.

\section{Funding}

This work was funded by grants from the National Natural Science Foundation of China (Grant no 71804125).

\section{Disclosure}

The authors report no conflicts of interest in this work.

\section{References}

1. Vogelmeier CF, Criner GJ, Martinez FJ, et al. Global strategy for the diagnosis, management, and prevention of chronic obstructive lung disease 2017 report. Am J Respir Crit Care Med. 2017;195 (5):557-582. doi:10.1164/rccm.201701-0218PP

2. Global Strategy for Diagnosis, Management and Prevention of COPD. The Global Initiative for Chronic Obstructive Lung Diseases (GOLD). Report; 2020. Available from: https:/goldcopd. org/gold-reports/. Accessed January 01, 2020.

3. Spruit MA, Pitta F, McAuley E, et al. Pulmonary rehabilitation and physical activity in patients with chronic obstructive pulmonary disease. Am J Respir Crit Care Med. 2015;192(8):924-933. doi:10.1164/rccm.201505-0929CI

4. World Health Organization. ICF- International Classification of Functioning, Disability and Health. Geneva: World Health Organization; 2001.

5. Liu A, Tao XN, Lin L, et al. Preliminary study on reliability and validity of ICF core function combination in chronic obstructive pulmonary disease. Chin J Physical Med Rehabil. 2009;(02):96-99. (in Chinese). doi:10.3760/cma.j.issn.0254-1424.2009.02.008

6. Lage SM, Jácome C, Oliveira A, et al. Validation of the International Classification of functioning, disability and health core set for obstructive pulmonary diseases in the perspective of adults with asthma. Disabil Rehabil. 2020;42(1):86-92. doi:10.1080/09638288.2018.1493159

7. Karlsson E, Mäki-Torkko E, Widén S, et al. Validation of the Brief International Classification of Functioning, disability and health (ICF) core set for hearing loss: an international multicentre study. Int J Audiol. 2020;18:1-9. doi:10.1080/14992027.2020.1846088

8. Liao HF, Hwang AW, Schiariti V, et al. Validating the ICF core set for cerebral palsy using a national disability sample in Taiwan. Disabil Rehabil. 2020;42(5):642-650. doi:10.1080/09638288.2018.1504328

9. Prodinger B, Salzberger T, Stucki G, et al. Measuring functioning in people with fibromyalgia (FM) based on the international classification of functioning, disability and health (ICF)-a psychometric analysis. Pain Pract. 2012;12(4):255-265. doi:10.1111/j.1533-2500.20 11.00488.x

10. Cieza A, Stucki G, Weigl M, et al. ICF Core Sets for low back pain. $J$ Rehabil Med. 2004;36:69-74. doi:10.1080/16501960410016037
11. Liao CD, Chiu YS, Ku JW, et al. Effects of elastic resistance exercise on postoperative outcomes linked to the ICF Core Sets for osteoarthritis after total knee replacement in overweight and obese older women with sarcopenia risk: a Randomized Controlled Trial. J Clin Med. 2020;9(7):2194. doi:10.3390/jcm9072194

12. Cieza A, Schwarzkopf S, Sigl T, et al. ICF core sets for osteoporosis. J Rehabil Med. 2004;36:81-86. doi:10.1080/16501960410016028

13. Stucki G, Cieza A, Geyh S, et al. ICF core sets for rheumatoid arthritis. J Rehabil Med. 2004;36:87-93. doi:10.1080/1650196041 0015470

14. You M, Fang W, Wang X, et al. Modelling of the ICF core sets for chronic ischemic heart disease using the LASSO model in Chinese patients. Health Qual Life Outcomes. 2018;16(1):139. doi:10.1186/ s12955-018-0957-0

15. Cieza A, Chatterji S, Andersen C, et al. ICF core sets for depression. J Rehabil Med. 2004;36:128-134. doi:10.1080/ 16501960410016055

16. Brach M, Cieza A, Stucki G, et al. ICF core sets for breast cancer. J Rehabil Med. 2004;36:121-127. doi:10.1080/ 16501960410016811

17. Geyh S, Cieza A, Schouten J, et al. ICF core sets for stroke. J Rehabil Med. 2004;36:135-141. doi:10.1080/16501960410016776

18. Cieza A, Kirchberger I, Biering-Sørensen F, et al. ICF core sets FOR individuals with spinal cord injury in the long-term context. Spinal Cord. 2010;48(4):305-312. doi:10.1038/sc.2009.183

19. Maritz R, Pongpipatpaiboon K, Melvin JL, et al. Content comparison of the spinal cord injury model system database to the ICF generic sets and core sets for spinal cord injury. Spinal Cord. 2019;57 (12):1023-1030. doi:10.1038/s41393-019-0326-9

20. Stucki A, Stoll T, Cieza A, et al. ICF Core Sets for obstructive pulmonary diseases. J Rehabil Med. 2004;36:114-120. doi:10.1080/ 16501960410016794

21. Rauch A, Kirchberger I, Stucki G, et al. Validation of the comprehensive ICF core set for obstructive pulmonary diseases from the perspective of physiotherapists. Physiother Res Int. 2009;14 (4):242-259. doi:10.1002/pri.448

22. Jobst A, Kirchberger I, Cieza A, et al. Content validity of the comprehensive ICF core set for chronic obstructive pulmonary diseases: an International Delphi Survey. Open Respir Med J. 2013;7:33-45. doi:10.2174/1874306401307010033

23. Marques A, Jácome C, Gonçalves A, et al. Validation of the comprehensive ICF core set for obstructive pulmonary diseases from the patient's perspective. Int $J$ Rehabil Res. 2014;37(2):152-158. doi:10.1097/MRR.0000000000000049

24. Marques A, Jácome C, Gabriel R, et al. Comprehensive ICF core set for obstructive pulmonary diseases: validation of the activities and participation component through the patient's perspective. Disabil Rehabil. 2013;35(20):1686-1691. doi:10.3109/09638288.2012.750691

25. Huang J, Reinhardt JD, Dai R, et al. Validation of the brief international classification of functioning, disability, and health core set for obstructive pulmonary disease in the Chinese context. Chron Respir Dis. 2019;16:1479973119843648. doi:10.1177/1479973119843648

26. Guo C, Liu Y, Hao S, et al. The reliability and validity of the "Activity and participation" component in the Brief ICF core set for chronic obstructive pulmonary diseases based on Rasch analysis. Int J Chron Obstruct Pulmon Dis. 2020;15:1191-1198. doi:10.2147/ COPD.S249704

27. Minglong W. SPSS Statistical Application Practice-Questionnaire Analysis and Applied Statistics. 1st ed. Beijing: Science Press; 2003.(in Chinese).

28. Bestall JC, Paul EA, Garrod R, et al. Usefulness of the Medical Research Council (MRC) dyspnoea scale as a measure of disability in patients with chronic obstructive pulmonary disease. Thorax. 1999;54(7):581-586. doi:10.1136/thx.54.7.581 
29. Downing SM. Reliability: on the reproducibility of assessment data. Med Educ. 2004;38(9):1006-1012. doi:10.1111/j.1365-2929.2004. 01932.x

30. Polit DF, Beck CT. The content validity index: are you sure you know what's being reported? Critique and recommendations. Res Nurs Health. 2006;29(5):489-497. doi:10.1002/nur.20147

31. Li-tze H, Bentler PM. Cutoff criteria for fit indexes in covariance structure analysis: conventional criteria versus new alternatives. Struct Equ Modeling. 1999;6(1):1-55. doi:10.1080/10705519909 540118

32. Marsh HW, Hau K-T, Balla JR, et al. Is more ever too much? The number of indicators per factor in confirmatory factor analysis. Multivariate Behav Res. 1998;33(2):181-220. doi:10.1207/s1532 7906mbr3302_1

33. Schober P, Boer C, Schwarte LA. Correlation coefficients: appropriate use and interpretation. Anesth Analg. 2018;126(5):1763-1768. doi:10.1213/ANE.0000000000002864

34. Wang Y, Xu J, Meng Y, et al. Role of inflammatory cells in airway remodeling in COPD. Int $J$ Chron Obstruct Pulmon Dis. 2018;13:3341-3348. doi:10.2147/COPD.S176122

35. Jinhua Y. Influencing factors of quality of life in patients with chronic obstructive pulmonary disease. Shanxi Medical University; 2008. (in Chinese).
36. Harvey BG, Strulovici-Barel Y, Kaner Robert J, et al. Risk of COPD with obstruction in active smokers with normal spirometry and reduced diffusion capacity. Eur Respir J. 2015;46:1589-1597. doi:10.1183/13993003.02377-2014

37. Boeck L, Gensmer A, Nyilas S, et al. Single-breath washout tests to assess small airway disease in COPD. Chest. 2016;150:1091-1100. doi:10.1016/j.chest.2016.05.019

38. Zeng GS. The relationship steps of 6MWT and COPD severity: a cross-sectional study. Southern Medical University; 2019. (in chinese).

39. Qian JH, Wu K, Luo HQ, Cao PY, Ren XH. Prevalence of loss of activities of daily living and influencing factors in elderly population in China. Zhonghua Liu Xing Bing Xue Za Zhi. 2016;37 (9):1272-1276. doi:10.3760/cma.j.issn.0254-6450.2016.09.018

40. Chen YH. Interpretation of GOLD global strategy for diagnosis, treatment and prevention of chronic obstructive pulmonary disease in 2020. Chin J Med Front. 2019;11(12):32-50. (in Chinese).

41. Marin JM, Carrizo SJ, Gascon M, et al. Inspiratory capacity, dynamichyperinflation, breathlessness, and exercise performance during the 6-minute walk test in chronic obstructive pulmonary disease. Am J Respir Crit Care Med. 2001;163(6):1395-1399. doi:10.1164/ ajrccm.163.6.2003172

\section{Publish your work in this journal}

The International Journal of COPD is an international, peer-reviewed journal of therapeutics and pharmacology focusing on concise rapid reporting of clinical studies and reviews in COPD. Special focus is given to the pathophysiological processes underlying the disease, intervention programs, patient focused education, and self management protocols. This journal is indexed on PubMed Central, MedLine and CAS. The manuscript management system is completely online and includes a very quick and fair peer-review system, which is all easy to use. Visit http://www.dovepress.com/testimonials.php to read real quotes from published authors. 